\title{
Internal fatigue crack initiation in drawn Ti-6Al-4V wires
}

J. Everaerts, B. Verlinden, M. Wevers

\section{Authors}

Joris Everaerts

Department of Materials Engineering, KU Leuven, Kasteelpark Arenberg 44, B-3001

Leuven, Belgium

joris.everaerts@mtm.kuleuven.be (corresponding author)

$+32 / 16321234$

Bert Verlinden

Department of Materials Engineering, KU Leuven, Kasteelpark Arenberg 44, B-3001 Leuven, Belgium

bert.verlinden@mtm.kuleuven.be

Martine Wevers

Department of Materials Engineering, KU Leuven, Kasteelpark Arenberg 44, B-3001

Leuven, Belgium

martine.wevers@mtm.kuleuven.be

\section{Abstract}

Fatigue cracks in titanium alloys are often found to initiate at faceted alpha grains. In the very high cycle fatigue regime, crack initiation tends to shift from the surface towards the interior of the material, and more initiation facets can be found on the fracture surface. In this study, fatigue tests were performed on drawn and heat-treated Ti-6Al-4V wires. Only a few samples fractured due to interior initiation. The facets at the initiation sites of these samples were not flat, but had markings on the nano-scale, and were highly inclined. A possible explanation for these aspects is the crystallographic texture of the wire, and a reflection is made on the suggested mechanisms of facet formation.

Keywords: Fatigue, Titanium, Ti-6Al-4V alloy, Subsurface initiation, Internal initiation, Fish-eye fracture, Facets, Crystallographic texture 


\section{Introduction}

Titanium alloys, and Ti-6Al-4V in particular, are frequently used for structural components, for instance in the aerospace industry, because of their good strength-toweight ratio, fatigue properties and corrosion resistance. However, because these alloys are often the choice for rotating components, which undergo cyclic loading, fatigue is still the main life-limiting factor. ${ }^{1}$ In order to optimize the fatigue performance of titanium alloys, it is necessary to have a clear understanding of the mechanisms that are involved in very high cycle fatigue cracking. More specifically, the crack initiation behaviour has to be clarified, because the initiation phase takes up most of the fatigue lifetime,$^{2-4}$ even up to $99 \%$ in the very high cycle fatigue regime $\left(>10^{7}\right.$ cycles $) .{ }^{5}$

The fatigue behaviour in this regime has become a topic of great interest because of the technological implications. The fatigue limit, which is often implemented as an important design parameter, cannot be used for metals subjected to low cyclic stresses, since different crack initiation and growth mechanisms become active below the threshold stress intensity factor range $\Delta \mathrm{K}_{\mathrm{th}}$, and failure can still occur after a large amount of cycles. ${ }^{6}$ In the very high cycle fatigue regime, it has been found that the location of crack initiation tends to shift from the surface towards the subsurface and interior of the material. ${ }^{3,5,7-20}$ This shift is coupled with a knee or sudden drop in the S-N curve around $10^{7}-10^{8}$ cycles, which means that the fatigue strength becomes much lower at these long lifetimes. ${ }^{13,14,21}$ Similar behaviour is found in certain high-strength steels and nickel alloys. ${ }^{5,22}$ Several factors have an influence on the internal initiation and crack growth behaviour of Ti-6Al-4V subjected to fatigue. A mean tensile stress facilitates internal crack initiation $8,14,16$ and generally leads to lower fatigue strength. ${ }^{9,23,24}$ Testing at cryogenic temperatures also causes a lower fatigue strength ${ }^{25}$ and a higher probability of internal crack initiation. ${ }^{20}$

Internal or subsurface cracks in titanium alloys, as a result of low stress cyclic loading, are found to initiate at facetted features, which can be seen on the fracture surface after failure. These facets are in fact fractured $\alpha$ grains, which have broken in a very planar manner. $3,7,8,10,11,13,14,17,20,25$ The observations of facets in literature tend to be different regarding their spatial and crystallographic orientation with respect to the loading axis, and regarding the presence or absence of marks on their surface. As a result, there is some discussion about their formation mechanism. Some authors conclude that a facet is the result of cleavage of an a grain, which occurs because dislocations in the neighbouring grains pile up at the grain boundary. This causes a local high stress, and if the a grain in question is oriented in such a way that no slip systems can be activated, it can fracture due to cleavage. ${ }^{3,10,13,26}$ On the other hand, several publications report that dislocation slip occurs in the $\alpha$ grain and leads to a facet under certain conditions. ${ }^{7,11,14}$, 21, 23, 25, 27-31 Even twinning has been suggested to be at the basis of facet formation. ${ }^{8}$ It is also important to take into account the fact that the environment for an internal crack 
will be different compared to a surface crack. If a crack initiates internally, the environment may be assumed to be almost vacuum. ${ }^{2}$ Some authors suggest that the threshold stress intensity factor range in vacuum is smaller than that in air when considering microstructurally short cracks, which could explain the growth of internal cracks from defects smaller than the critical defect size as measured in air. ${ }^{11}$ Others, however, suspect that a local cyclic erosion process can take place due to the lack of oxygen in an interior crack, which overtime reduces the crack closure level and under certain conditions leads to crack growth. ${ }^{17}$ Fractographical studies of Ti-6Al-4V subjected to fatigue testing in vacuum do reveal facetted features in the crack growth region, which further supports the notion that the crack growth mechanism is influenced by the lack of internal environment. ${ }^{32,33}$

In most cases, the facets on the fracture surfaces appear to be completely flat and do not show any markings or traces. ${ }^{3}, 7,8,10,11,13,17,20,25$ However, a few publications mention the presence of a radial pattern within one facet, $, 4,14,26$ and slip-like patterns have been noticed on facets in a Ti-22V-4Al alloy. ${ }^{28}$ Furthermore, fatigue testing using a spike loaded spectrum can lead to markings on facets. ${ }^{21}$

Since all of the current research on facets in internal fatigue crack initiation is limited to testing on forged plates or rods, the main objective of this study is to investigate this phenomenon in drawn Ti-6Al-4V wire. Because of the different production method, the microstructure and crystallographic texture of these wires is different compared to forged products. Therefore, fatigue testing of these wires can lead to new insights in the internal crack formation mechanism, which can be used to critically reflect on the varying suggestions in literature. 


\section{Experimental methods}

The Ti-6Al-4V (ASTM B863, grade 5) wire used in this study has a diameter of $1 \mathrm{~mm}$, and was supplied in a coil. Table 1 shows the composition as determined by the manufacturer.

Table 1: Chemical composition of the wire, as determined by the manufacturer (wt-\%)

\begin{tabular}{|c|c|c|c|c|c|c|c|c|}
\hline $\mathrm{Al}$ & $\mathrm{V}$ & $\mathrm{Fe}$ & $\mathrm{C}$ & $\mathrm{N}$ & $\mathrm{H}$ & $\mathrm{O}$ & Others & $\mathrm{Ti}$ \\
\hline 6.1 & 4.1 & $\leq 0.10$ & $\leq 0.01$ & $\leq 0.01$ & $\leq 0.01$ & $\leq 0.009$ & $\leq 0.2$ & bal \\
\hline
\end{tabular}

The material was heat treated in vacuum $\left(<1 \times 10^{-3} \mathrm{~Pa}\right)$ at $1193 \mathrm{~K}$ for 10 hours followed by furnace cooling. The wire was then cut in samples of approximately $11 \mathrm{~cm}$, and straightened by applying a deformation of $1 \%$ plastic strain. Next, the wires were subjected to a stress relief treatment in vacuum $\left(<1 \times 10^{-3} \mathrm{~Pa}\right)$ at $873 \mathrm{~K}$ for 1 hour followed by furnace cooling. The resultant microstructure is primarily equiaxed $\alpha$ phase (hcp) with partially transformed $\beta$ (bcc) at the grain boundaries, as can be seen in the backscattered electron image of the cross-section and longitudinal section of the wire (Figure 1). The average $\alpha$ grain size is approximately $5 \mu \mathrm{m}$, as calculated from an EBSD measurement.
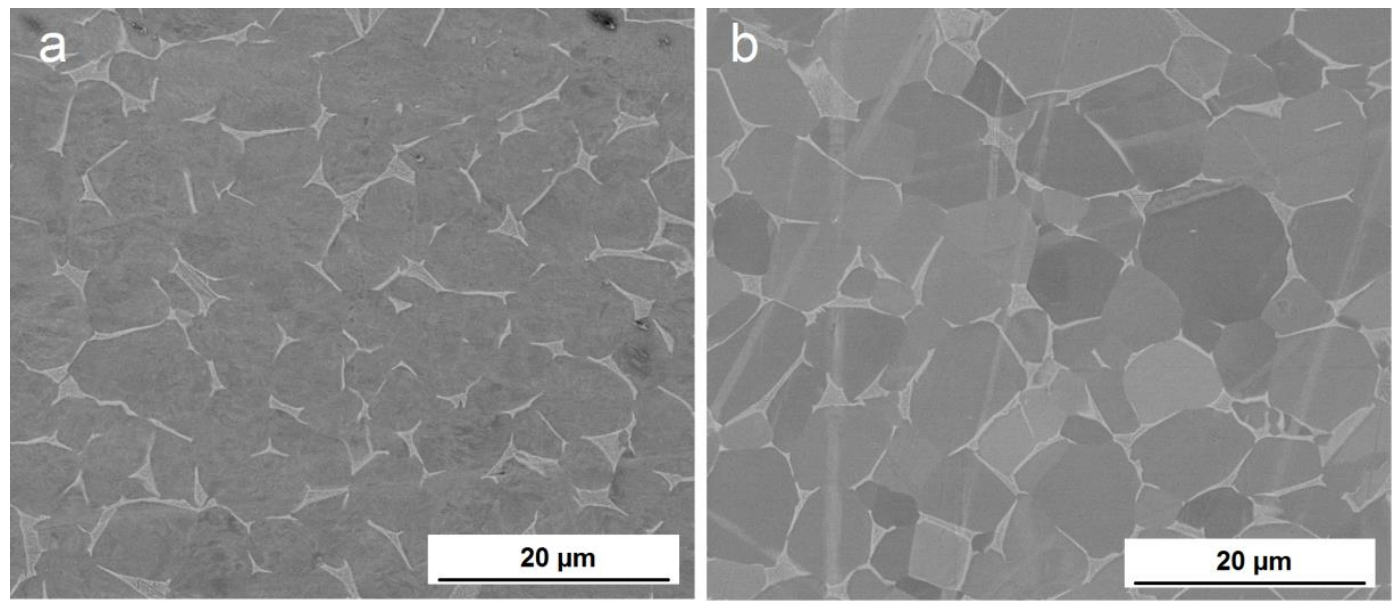

Figure 1: Backscattered electron images of the Ti-6Al-4V wire; a cross-section; b longitudinal section

Prior to fatigue testing, the wires were electropolished in order to reduce the probability of surface initiation from defects at the surface or surface irregularities. The wires were electrochemically polished for 10 minutes in an electrolyte containing 55 vol.-\% $\mathrm{CH}_{3} \mathrm{COOH}, 30$ vol.- $\% \mathrm{H}_{2} \mathrm{SO}_{4}$ and 15 vol.- $\% \mathrm{HF}(48 \%$ pure) with a current density of 1.2 $\mathrm{mA} \mathrm{mm}{ }^{-2}$. Further details of this electrochemical polishing treatment are reported by Pyka et al. ${ }^{34}$ The wires were then cut to approximately $9 \mathrm{~cm}$ and glued with two grooved plates on each side, using Araldite Rapid epoxy adhesive. The grooved plates, 
schematically shown in Figure 2, have a length $L$ of $20 \mathrm{~mm}$, width $W$ of $15 \mathrm{~mm}$ and a thickness of $1 \mathrm{~mm}$. The groove has a width of $1 \mathrm{~mm}$ and a depth of $0.5 \mathrm{~mm}$. Consequently, after electrochemical polishing and clamping, the samples had a diameter of approximately $0.95 \mathrm{~mm}$, and a free gauge length of approximately $50 \mathrm{~mm}$, but prior to testing both values were more accurately measured for each individual sample with a digital calliper. Afterwards, the wire along the gauge length was coated with Sicomet 85 cyanoacrylate glue, in order to protect the wire surface from the environment.

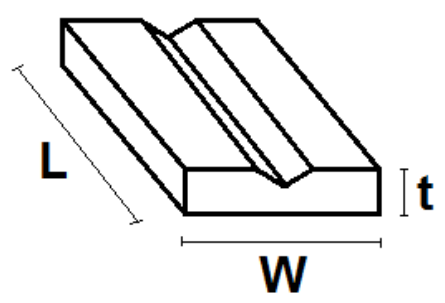

Figure 2: Drawing of a grooved plate used for clamping the wire during fatigue testing ( $L=20 \mathrm{~mm}$, $\mathrm{W}=15 \mathrm{~mm}, \mathrm{t}=1 \mathrm{~mm})$

Load controlled fatigue testing was performed on an Instron ElectroPuls E3000 instrument, at a load ratio of 0.1 and frequency of $60 \mathrm{~Hz}$ (sine wave). The maximum stress level was $750 \mathrm{MPa}$, which is approximately $90 \%$ of the yield stress $\left(\sigma_{\mathrm{y}, 0.2 \%=828}\right.$ $\mathrm{MPa}$ ). This relatively high stress level was chosen in order to limit the testing time. Microstructure imaging and fractographic examinations were performed using a FEI Nova NanoSEM 450. Quantitative tilt fractography, used for measuring facet angles, was done by taking two images of the same area, one with minus ten degrees tilt and one with ten degrees tilt around the horizontal axis, and processing them with Alicona MeX software. 


\section{Results and discussion}

Figure 3 shows the fatigue life as a function of maximum applied stress for all samples that failed within the gauge section. Samples that failed inside the clamps have been omitted from this graph. Although the maximum stress is the same for all samples, it is clear that there is a rather large variability in the fatigue life. This spread of almost two orders of magnitude is not uncommon for the Ti-6Al-4V alloy, 8, 11,35 and in this case can be explained by the fact that the applied stress level is chosen to be close to the transition point from surface to interior initiation, the so-called "knee" in the S-N curve. ${ }^{13}$, 14, 21 In fact, three samples have failed as a result of internal crack development, marked as samples $A, B$ and $C$ in Figure 3 . It should be noted that there is no well-defined transition from surface to internal initiation in terms of fatigue life. There are two samples with surface-initiated failure, for example sample ' $s$ ', with a higher fatigue life than sample A.

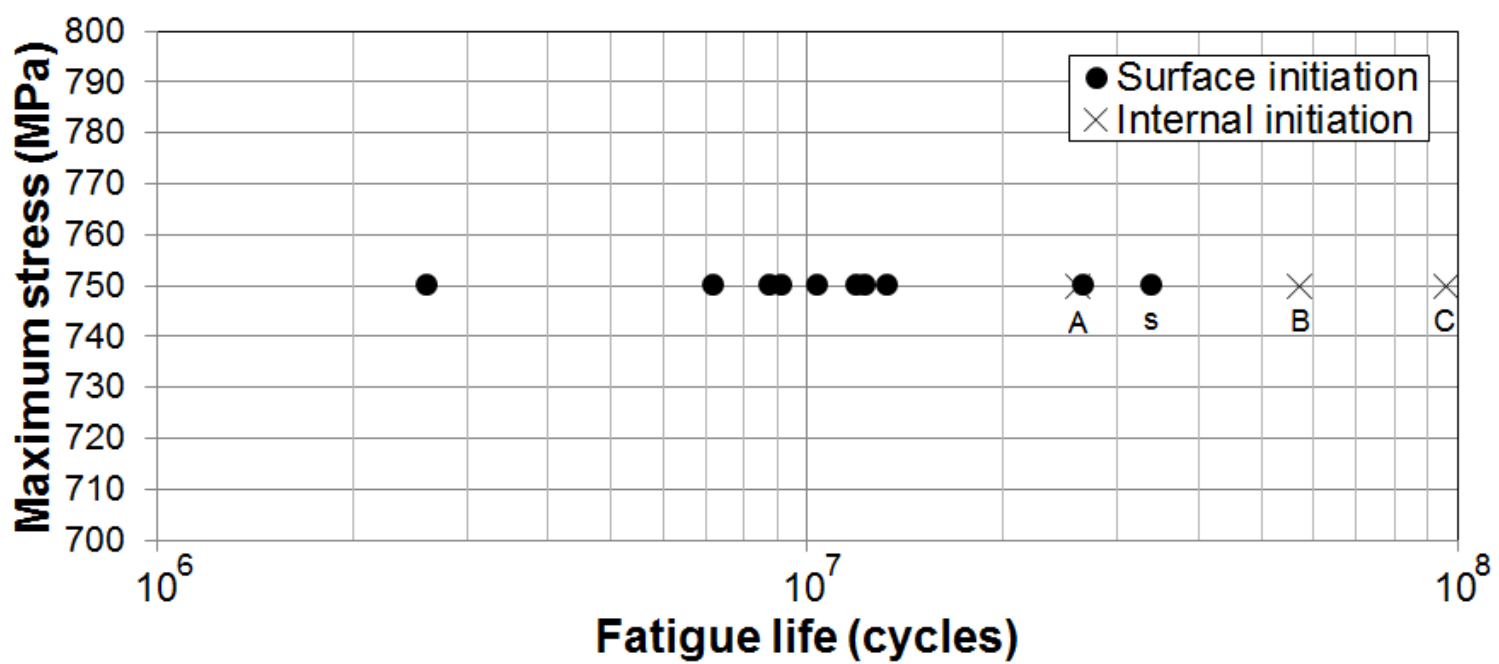

Figure 3: Fatigue life variability of Ti-6Al-4V, showing samples with surface and internal initiation

SEM fractographs of the fracture surfaces of four samples at a low magnification are shown in Figure 4. A typical example of a surface-initiated failure can be seen in Figure 4a (sample s), whilst Figure $4 \mathrm{~b}$ and Figure $4 \mathrm{c}$ show two samples that failed due to subsurface-initiated cracks (samples $A$ and $C$, respectively). The fractograph in Figure $4 d$ shows sample $B$, which failed due to internal crack initiation, forming a so-called 'fisheye' fracture surface, which has a rough central crack initiation area, surrounded by a circular internal crack growth area. It should be noted that the fatigue life of the subsurface-initiated sample $C$ in Figure $4 \mathrm{c}, 9.6 \times 10^{7} \mathrm{cycles}$, is higher than the fatigue life of sample B with the fish-eye failure in Figure $4 \mathrm{~d}, 5.7 \times 10^{7}$ cycles, even though the latter has a crack initiation location which lies further away from the sample surface. This is in 
accordance with the findings of Yokoyama et al., ${ }^{20}$ who concluded that the fatigue life does not correlate with the location of the internal crack initiation site.
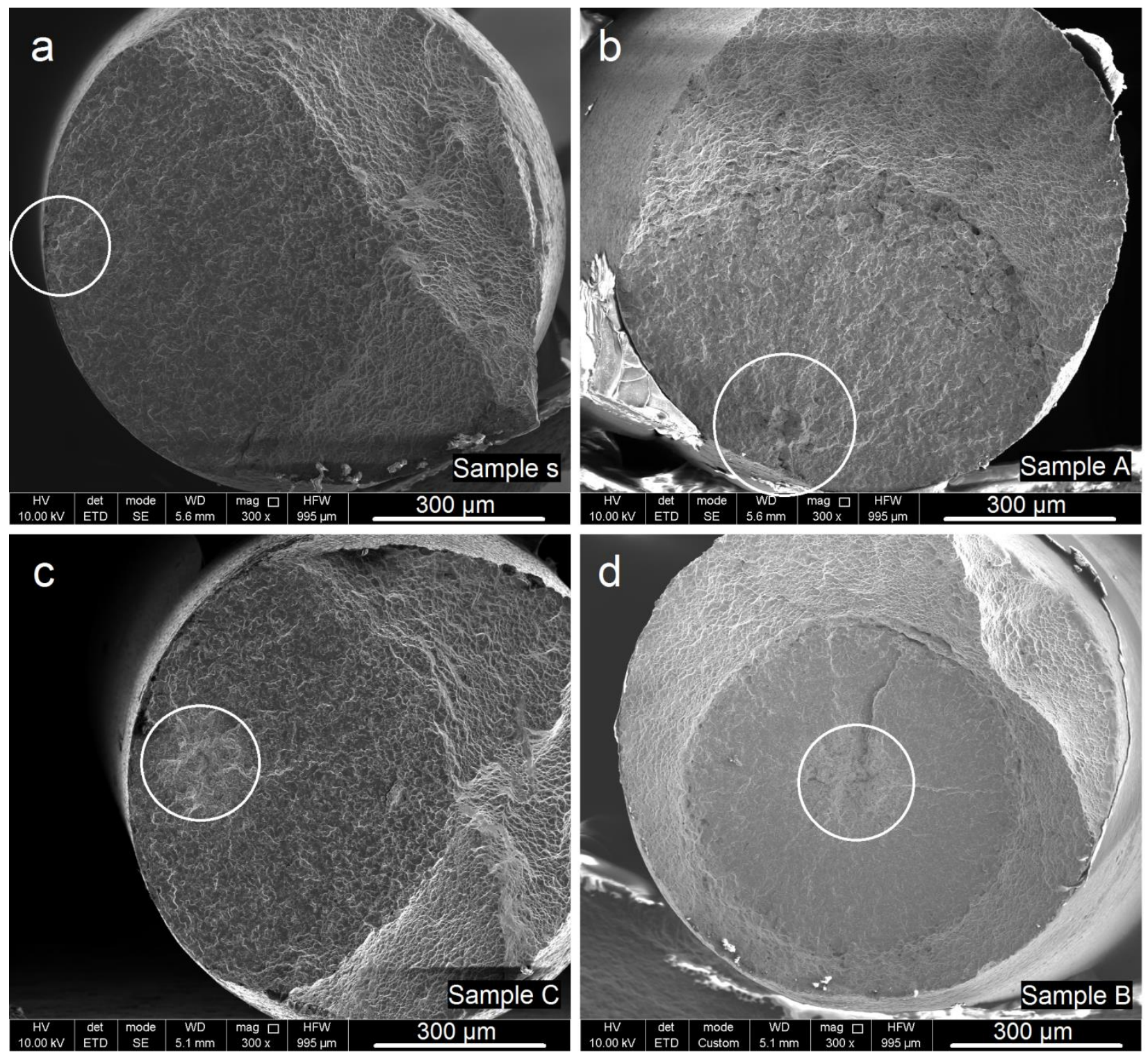

Figure 4: SEM fractographs at 300x magnification of four samples, white circles indicate the initiation area; a $3.4 \times 10^{7}$ cycles to failure (sample s); b $2.6 \times 10^{7}$ cycles to failure (sample A); c $9.6 \times 10^{7}$ cycles to failure (sample C); $d 5.7 \times 10^{7}$ cycles to failure (sample B)

The samples in Figure $4 \mathrm{~b}(\mathrm{~A}$, subsurface initiation) and Figure $4 \mathrm{~d}$ ( $\mathrm{B}$, fish-eye) are selected for a more detailed fractographic analysis. For both samples, the initiation area is found to contain many facets, as is shown in Figure 5 . Both fracture surfaces have approximately 50 individual facets each. At higher magnification, it becomes clear that the facets on the fracture surfaces are not smooth, but instead display markings or some roughness on the nano-scale. As stated in the introduction, only a few publications mention the presence of markings on the facets, either in the form of a radial pattern ${ }^{4,14}$, 
${ }^{26}$, or as a slip-like pattern in a Ti-22V-4Al alloy. ${ }^{28}$ In this case, the markings are not radial, but instead are more linear, which suggests that they could be slip traces.
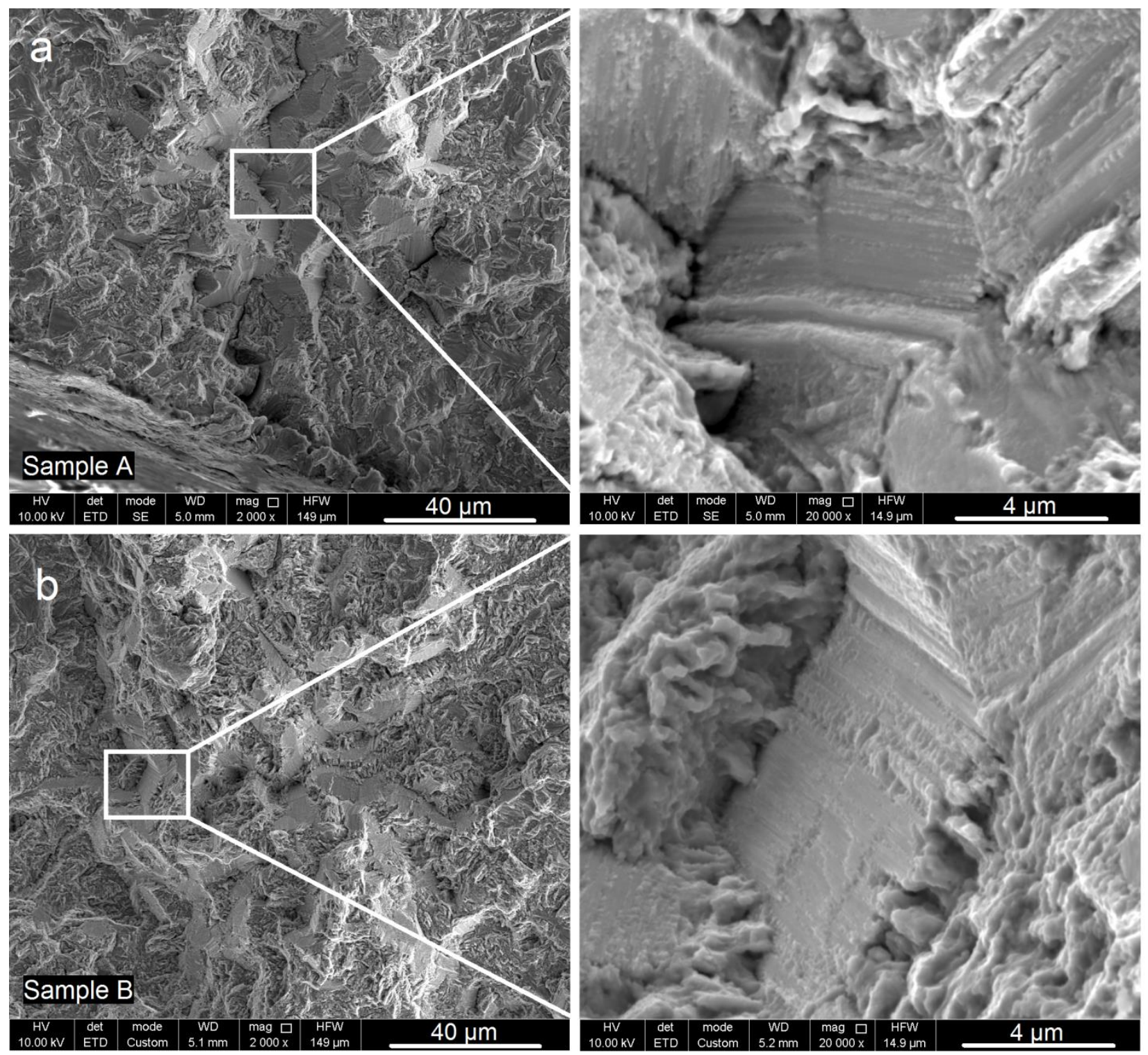

Figure 5: SEM fractographs at $2000 x$ and $20000 x$ magnification of two selected samples; a $2.6 \times 10^{7}$ cycles to failure (sample $A$, subsurface); b $5.7 \times 10^{7}$ cycles to failure (sample $B$, fish-eye)

However, some of the nano-roughness features deviate from the linear pattern, as can be seen for example in Figure 6 . The two images in this figure are taken from both opposite fracture surfaces of sample $B$, at the same location. The white ellipse indicates a non-linear marking on a facet. Interestingly, on one fracture surface it appears that the pattern consists of material on top of the facet (Figure 6 left), whilst on the opposing fracture surface the same pattern appears to be pressed into the facet (Figure 6 right), which suggests that some material was transferred between the two opposing crack surfaces. The appearance of these markings and the apparent material transfer between 
both sides of the fracture surface draws similarities with galling and cold welding patterns seen in adhesive wear. The presence of a wear mechanism during internal fatigue crack initiation and growth in Ti-6Al-4V has already been suggested by McEvily et al., ${ }^{17}$ who stated that the lack of oxygen in an internal crack can allow a local erosion process to take place, which slowly reduces the crack closure level until the arrested crack is able to propagate further. However, the only evidence of their mechanism were the rounded fractographic features surrounding the facets (see Figure 7), which can also be seen in this work (Figure 5 and Figure 6). The markings on facets in this work are additional signs that there could indeed be a wear mechanism involved in internal crack initiation in Ti-6Al-4V.
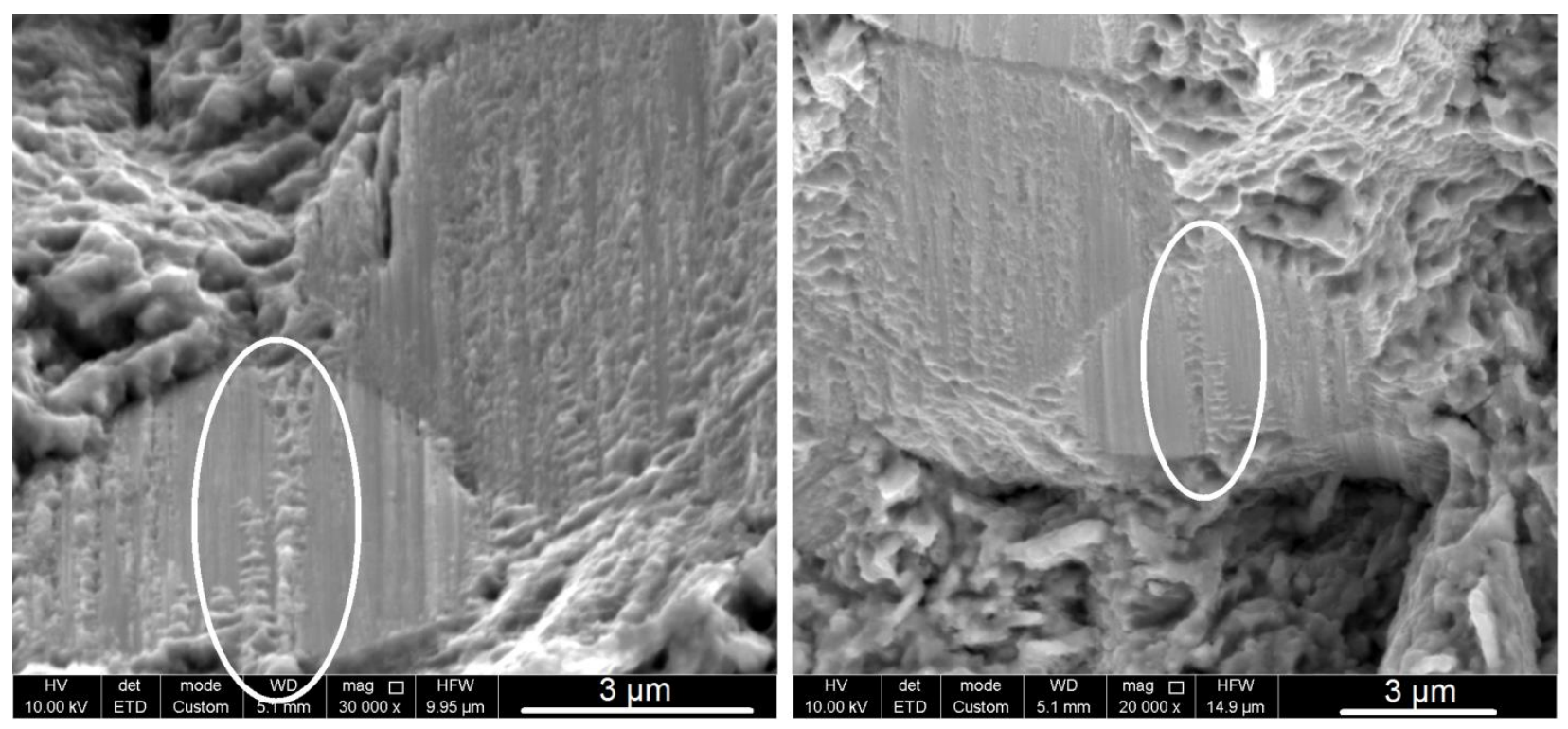

Figure 6: SEM fractographs of sample $B\left(5.7 \times 10^{7}\right.$ cycles to failure), taken at the same location on both opposite fracture surfaces (left and right)

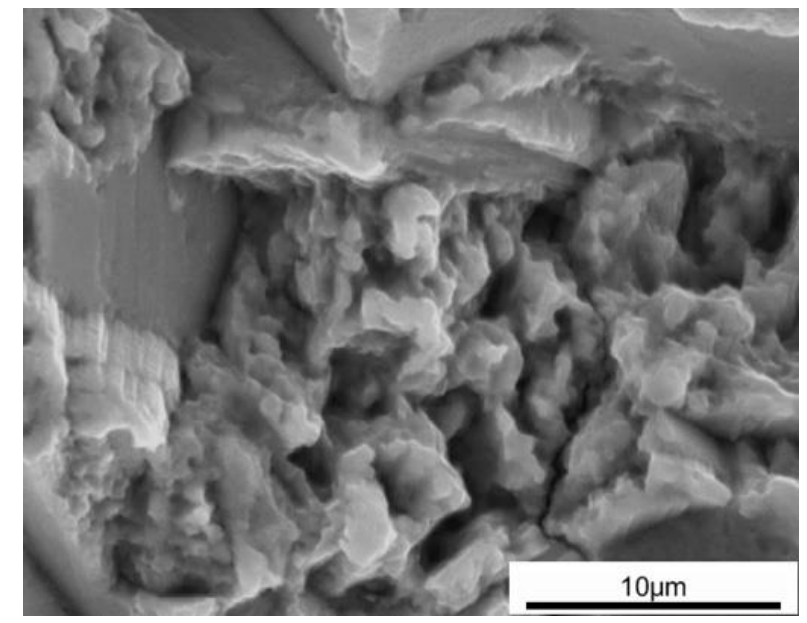

Figure 7: Rounded fractographic features on the fracture surface of a subsurface-initiated Ti-6Al$4 \mathrm{~V}$ sample $^{36}$ 
The explanation of the presence of markings on facets in these experiments, and the absence of these markings in similar publications, $3,7,8,10,11,17,20$ can be sought in the crystallographic texture of the alpha phase, which is different for the wire-drawn samples in this study compared to the forged rods used in other studies. It has been reported that facets are parallel to certain crystallographic planes, in most cases the basal plane ${ }^{7,12}$, $27,32,37,38$ or the prismatic plane,, 27 which means that the spatial angles of the facet planes are linked to the texture. The alpha phase texture of the wire used in this study is shown in Figure 8. It can be seen that there is a high tendency for grains to be oriented with the normal direction of the $\{10 \overline{1} 0\}$ planes parallel to the wire axis, as well as a tendency for grains to be oriented with the normal direction of the $\{10 \overline{1} 0\}$ planes rotated approximately $60^{\circ}$ from the wire axis. The spatial angle distribution of the facets on the fracture surfaces of the selected fish-eye $(B)$ and subsurface $(A)$ sample is shown in Figure 9. It is noted that this distribution is very similar for both samples, which further insinuates that the facet formation mechanism is related to the crystallographic texture. The spatial angles of facets in these samples deviate from the facet angles found in similar publications. Jha et al. ${ }^{7}$ reported that the majority of facet angles for a fish-eye sample were between $30^{\circ}$ and $60^{\circ}$, while Bantounas et al. ${ }^{38}$ found that the angles of initiation facets for a subsurface-initiated sample were between $15^{\circ}$ and $40^{\circ}$. These angles are considerably smaller than those found in this work.

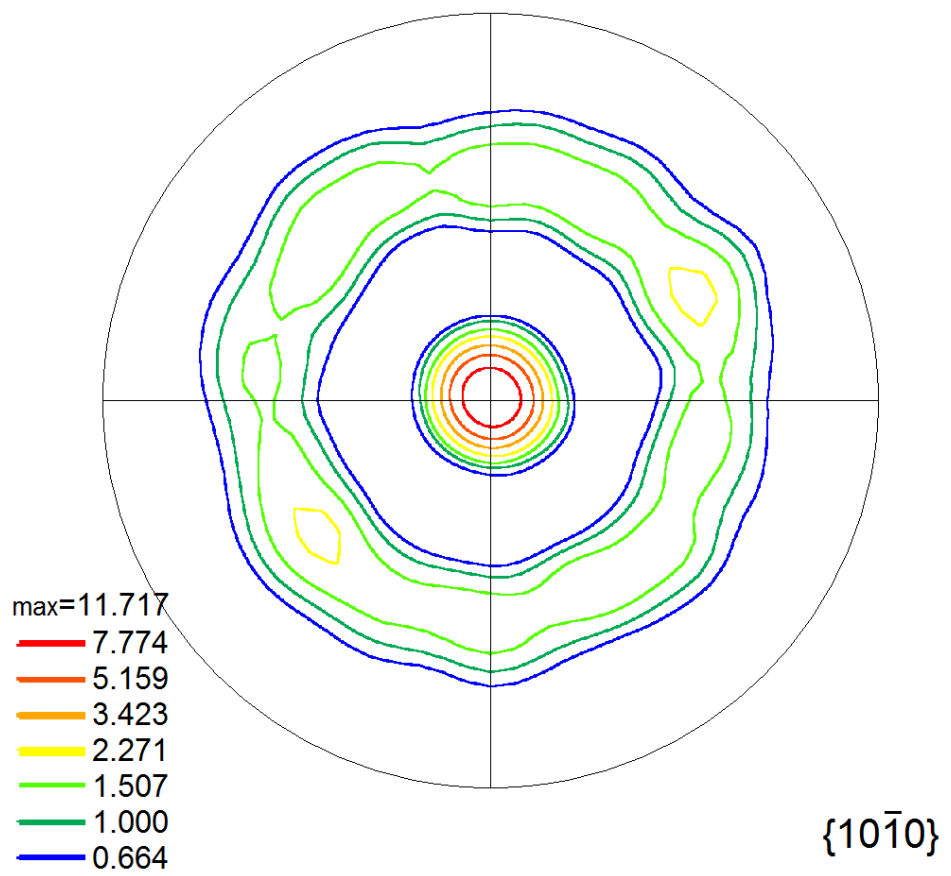

Figure 8: $\{10 \overline{1} 0\}$ pole figure of alpha phase, obtained from an EBSD measurement on sample cross-section, wire axis is perpendicular to the paper 


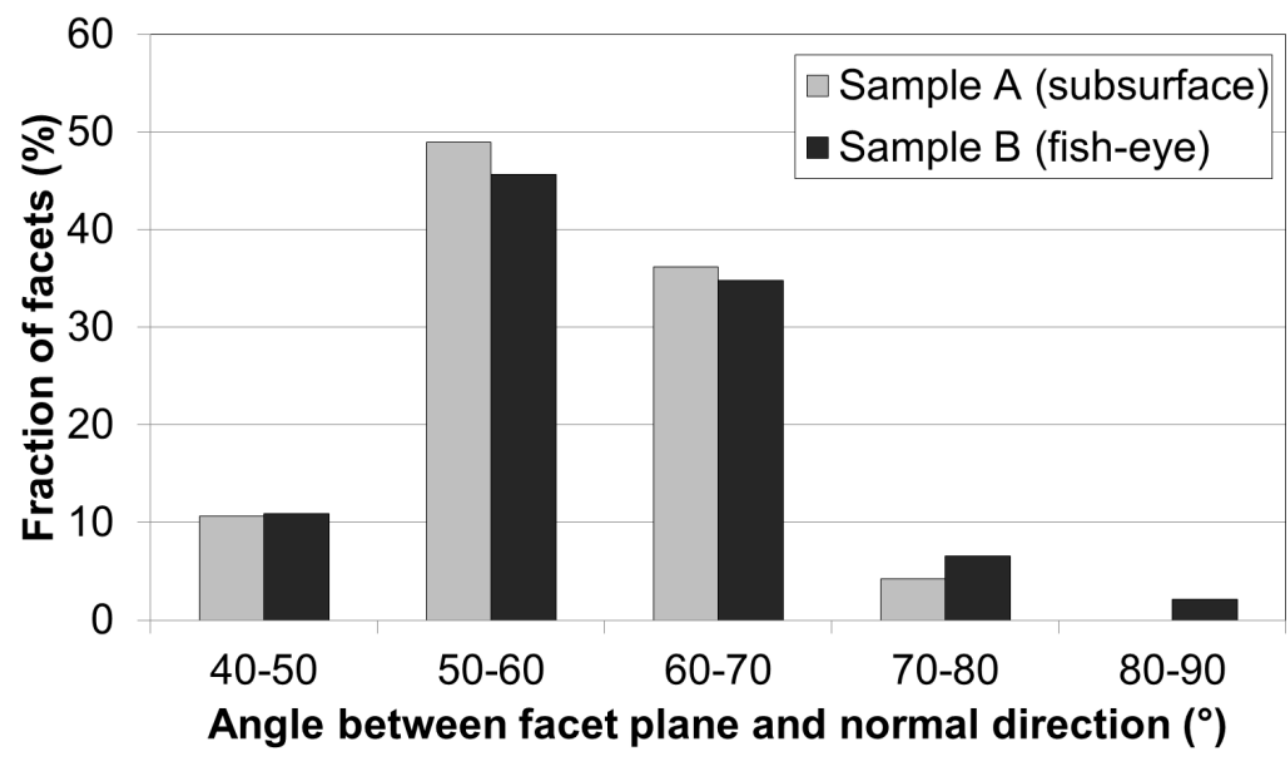

Figure 9: Distribution of spatial angle of facets (between facet plane and normal direction) for both sample A (subsurface, $2.6 \times 10^{7}$ cycles to failure) and sample B (fish-eye, $5.7 \times 10^{7}$ cycles to failure)

If the markings on the facets are indeed the result of a local internal wear process, as suggested by McEvily et al., ${ }^{17}$ then it is clear that the facet angle is an important parameter in this process. Given the fact that the fatigue tests are performed in tensiontension (load ratio of 0.1 ), a certain amount of crack closure is also required if there is to be contact between two opposing crack surfaces. It is plausible that the specific crystallographic texture of the Ti-6Al-4V wire used in this work has caused the facets to be more inclined with respect to the loading direction, which in turn has resulted in the presence of wear markings on the facets. On the other hand, some of the markings on the facets could simply be slip traces. If it is assumed that the facets are parallel to a certain crystallographic plane, Figure 10 illustrates that in this case it is most likely to be the prismatic plane. This figure shows the orientation of the hexagonal lattice which represents the two most prominent texture features, being the normal direction of the $\{10 \overline{1} 0\}$ planes parallel to the wire axis, and the normal direction of the $\{10 \overline{1} 0\}$ planes rotated approximately $60^{\circ}$ from the wire axis (see Figure 8 ). Combined with the fact that most facets lie at an angle of approximately $60^{\circ}$ to the normal direction (see Figure 9), it is plausible that they were formed on one of the prismatic planes oriented with the normal direction rotated $60^{\circ}$ from the wire axis (see Figure 10, planes 2, 3, 5 and 6). It is interesting to note that in this case no facets have formed on the prismatic planes numbered 1 and 4 in Figure 10, since these would have had an angle of approximately $0^{\circ}$ with respect to the normal direction and such angles have not been measured (see Figure 9). Bridier et al. ${ }^{27}$ also suggested that the mechanism of prismatic crack formation involves slip band formation, while crack formation on the basal plane involves cleavage due to the fact that slip is restricted on this plane. This could explain the fact that the facets in this work show markings, while the basal facets in similar studies do not. In 
order to verify whether the facet planes are indeed parallel to a prismatic plane, FIB/EBSD experiments are currently being performed on the selected samples. The results of these experiments will also indicate whether at least some of the markings on the facets are slip traces, since these should correspond to certain slip systems.

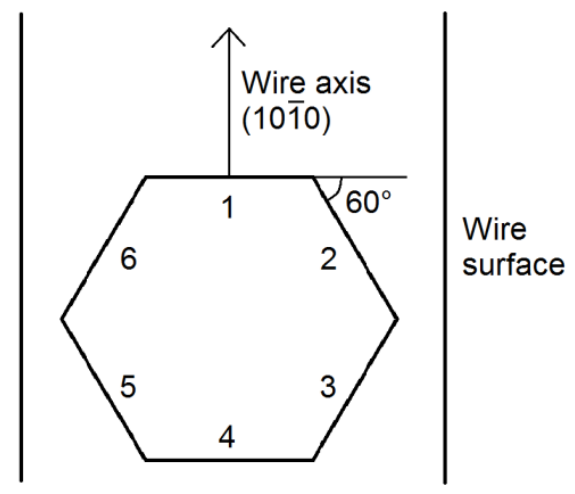

Figure 10: Representation of crystal orientation present in the texture of the wire, and the six prismatic planes of the hexagonal lattice 


\section{Conclusions}

Fatigue tests were performed on drawn, heat-treated and electropolished Ti-6Al-4V wires in order to investigate the role of alpha facets on the fracture surface in the case of internal fatigue crack initiation. Fractographic inspection revealed that three samples failed due to internal crack initiation: two subsurface-initiated cracks, and one 'fish-eye' crack. The initiation area of all three samples contained a large amount of facets. These facets were not smooth, but contained markings or roughness on the nano-scale. Two possible explanations are given for the presence of these markings: a local internal wear process and traces of slip. The crystallographic texture of the material and the spatial distribution of the facet angles were measured. The facets lie at a relatively high angle with respect to the normal direction, mostly between $50^{\circ}$ and $70^{\circ}$. The facet planes are most likely parallel to prismatic lattice planes. FIB/EBSD experiments are ongoing in order to measure the crystallographic orientation of the facets and to verify whether the markings on the facets can be slip traces.

\section{Acknowledgements}

The authors acknowledge financial support from the Interuniversity Attraction Poles Program from the Belgian state through the Belgian Policy agency; contract IAP7/21 "INTEMATE". 


\section{References}

1. R. R. Boyer: 'An overview on the use of titanium in the aerospace industry', Mater. Sci. Eng. A-Struct. Mater. Prop. Microstruct. Process., 1996, 213(1-2), 103-114.

2. I. Marines-Garcia, P. C. Paris, H. Tada, C. Bathias, and D. Lados: 'Fatigue crack growth from small to large cracks on very high cycle fatigue with fish-eye failures', Eng. Fract. Mech., 2008, 75(6), 1657-1665.

3. J. H. Zuo, Z. G. Wang, and E. H. Han: 'Effect of microstructure on ultra-high cycle fatigue behavior of Ti-6Al-4V', Mater. Sci. Eng. A-Struct. Mater. Prop. Microstruct. Process., 2008, 473(1-2), 147-152.

4. M. Hamada and O. Umezawa: 'Evaluation of Subsurface Fatigue Crack Life in Forged Ti-6Al-4V Alloys at Cryogenic Temperatures', ISIJ Int., 2009, 49(1), 124131.

5. V. Kazymyrovych, Very high cycle fatigue of engineering materials: A literature review. 2009.

6. C. Bathias: 'There is no infinite fatigue life in metallic materials', Fatigue Fract. Eng. Mater. Struct., 1999, 22(7), 559-565.

7. S. K. Jha, C. J. Szczepanski, P. J. Golden, W. J. Porter, and R. John: 'Characterization of fatigue crack-initiation facets in relation to lifetime variability in Ti-6Al-4V', Int. J. Fatigue, 2012, 42, 248-257.

8. Y. Furuya and E. Takeuchi: 'Gigacycle fatigue properties of Ti-6Al-4V alloy under tensile mean stress', Mater. Sci. Eng. A-Struct. Mater. Prop. Microstruct. Process., 2014, 598, 135-140.

9. A. Atrens, W. Hoffelner, T. W. Duerig, and J. E. Allison: 'Subsurface crack initiation in high cycle fatigue in Ti6Al4V and in a typical martensitic stainlesssteel', Scripta Metallurgica, 1983, 17(5), 601-606.

10. D. F. Neal and P. A. Blenkinsop: 'Internal fatigue origins in alpha-beta titaniumalloys', Acta Metallurgica, 1976, 24(1), 59-63.

11. H. Oguma and T. Nakamura: 'The effect of microstructure on very high cycle fatigue properties in Ti-6Al-4V', Scr. Mater., 2010, 63(1), 32-34.

12. R. K. Nalla, B. L. Boyce, J. P. Campbell, J. O. Peters, and R. O. Ritchie: 'Influence of microstructure on high-cycle fatigue of Ti-6Al-4V: Bimodal vs. lamellar structures', Metall. Mater. Trans. A-Phys. Metall. Mater. Sci., 2002, 33(3), 899-918.

13. S. K. Jha and K. S. R. Chandran: 'An unusual fatigue phenomenon: duality of the S-N fatigue curve in the beta-titanium alloy Ti-10V-2Fe-3Al', Scr. Mater., 2003, 48(8), 1207-1212.

14. O. Umezawa and K. Nagai: 'Subsurface crack generation in high-cycle fatigue for high strength alloys', ISIJ Int., 1997, 37(12), 1170-1179.

15. E. Takeuchi, Y. Furuya, N. Nagashima, and S. Matsuoka: 'The effect of frequency on the giga-cycle fatigue properties of a Ti-6Al-4V alloy', Fatigue Fract. Eng. Mater. Struct., 2008, 31(7), 599-605.

16. H. Oguma and T. Nakamura: 'The effect of stress ratios on very high cycle fatigue properties of Ti-6Al-4V', in 'Advances in Fracture and Failure Prevention, Pts 1 and 2', (eds. K. Kishimoto, et al.), 1227-1232; 2004, Zurich-Uetikon, Trans Tech Publications Ltd. 
17. A. J. McEvily, T. Nakamura, H. Oguma, K. Yamashita, H. Matsunaga, and M. Endo: 'On the mechanism of very high cycle fatigue in Ti-6Al-4V', Scr. Mater., 2008, 59(11), 1207-1209.

18. S. Heinz, F. Balle, G. Wagner, and D. Eifler: 'Analysis of fatigue properties and failure mechanisms of Ti6Al4V in the very high cycle fatigue regime using ultrasonic technology and 3D laser scanning vibrometry', Ultrasonics, 2013, 53(8), 1433-1440.

19. C. Bathias, L. Drouillac, and P. Le Francois: 'How and why the fatigue S-N curve does not approach a horizontal asymptote', Int. J. Fatigue, 2001, 23, S143-S151.

20. H. Yokoyama, O. Umezawa, K. Nagai, and T. Suzuki: 'Distribution of internal crack initiation sites in high-cycle fatigue for titanium alloys', ISIJ Int., 1997, 37(12), 1237-1244.

21. N. E. Paton, J. C. Williams, J. C. Chesnutt, and A. W. Thompson, The effects of microstructure on the fatigue and fracture of commercial titanium alloys, in Specialists meeting on alloy design for fatigue and fracture resistance : papers presented at the 40th meeting of the structures and materials panel in Brussels, Belgium, 13-19 April 1975. 1976, London Agard, 1976: London.

22. K. Lambrighs, M. Wevers, B. Verlinden, and I. Verpoest: 'A fracture mechanics approach to fatigue of heavily drawn steel wires', 11th International Conference on the Mechanical Behavior of Materials (Icm11), 2011, 10, 3259-3266.

23. R. K. Steele and A. J. McEvily: 'High-cycle fatigue behavior of Ti-6Al-4V alloy', Eng. Fract. Mech., 1976, 8(1), 31-37.

24. J. Lindemann and L. Wagner: 'Mean stress sensitivity in fatigue of alpha, (alpha+beta) and beta titanium alloys', Mater. Sci. Eng. A-Struct. Mater. Prop. Microstruct. Process., 1997, 234, 1118-1121.

25. Y. Ono, T. Yuri, H. Sumiyoshi, S. Matsuoka, and T. Ogata: 'Subsurface fracture in high-cycle fatigue at cryogenic temperatures in Ti-5 \% Al-2.5 \% Sn extra low interstitial alloy', Mater. Trans., 2003, 44(9), 1702-1705.

26. S. G. Ivanova, R. R. Biederman, and R. D. Sisson: 'Investigation of fatigue crack initiation in Ti-6Al-4V during tensile-tensile fatigue', J. Mater. Eng. Perform., 2002, 11(2), 226-231.

27. F. Bridier, P. Villechaise, and J. Mendez: 'Slip and fatigue crack formation processes in an alpha/beta titanium alloy in relation to crystallographic texture on different scales', Acta Mater., 2008, 56(15), 3951-3962.

28. K. Tokaji, K. Ohya, and H. Kariya: 'Subsurface fatigue crack initiation in beta titanium alloys', Fatigue Fract. Eng. Mater. Struct., 2000, 23(9), 759-766.

29. M. R. Bache: 'Processing titanium alloys for optimum fatigue performance', Int. J. Fatigue, 1999, 21, S105-S111.

30. A. L. Pilchak, A. Bhattacharjee, A. H. Rosenberger, and J. C. Williams: 'Low Delta $\mathrm{K}$ faceted crack growth in titanium alloys', Int. J. Fatigue, 2009, 31(5), 989-994.

31. I. Bantounas, D. Dye, and T. C. Lindley: 'The role of microtexture on the faceted fracture morphology in Ti-6Al-4V subjected to high-cycle fatigue', Acta Mater., 2010, 58(11), 3908-3918.

32. C. Sarrazin-Baudoux: 'Environmentally Influenced Fatigue Crack Path in Titanium Alloys', Proceedings of Fatigue Crack Paths (FCP 2003), Parma, Italy, 2003. 
33. M. R. Bache, W. J. Evans, and M. McElhone: 'The effects of environment and internal oxygen on fatigue crack propagation in Ti-6Al-4V', Mater. Sci. Eng. AStruct. Mater. Prop. Microstruct. Process., 1997, 234, 918-922.

34. G. Pyka, A. Burakowski, G. Kerckhofs, M. Moesen, S. Van Bael, J. Schrooten, and M. Wevers: 'Surface Modification of Ti6Al4V Open Porous Structures Produced by Additive Manufacturing', Adv. Eng. Mater., 2012, 14(6), 363-370.

35. T. Akahori and M. Niinomi: 'Fracture characteristics of fatigued Ti-6Al-4V ELI as an implant material', Mater. Sci. Eng. A-Struct. Mater. Prop. Microstruct. Process., 1998, 243(1-2), 237-243.

36. H. Oguma: 'Very High Cycle Fatigue Properties of Ti-6Al-4V Alloy', PhD thesis, Hokkaido University, 2006.

37. H. Knobbe, P. Koster, H. J. Christ, C. P. Fritzen, and M. Riedler: 'Initiation and Propagation of Short Fatigue Cracks in Forged Ti6Al4V', Fatigue 2010, 2010, 2(1), 931-940.

38. I. Bantounas, D. Dye, and T. C. Lindley: 'The effect of grain orientation on fracture morphology during high-cycle fatigue of Ti-6Al-4V', Acta Mater., 2009, 57(12), 3584-3595. 


\section{Figure and table captions}

Figure 1: Backscattered electron images of the Ti-6Al-4V wire; a cross-section; b longitudinal section

Figure 2: Drawing of a grooved plate used for clamping the wire during fatigue testing $(\mathrm{L}=20 \mathrm{~mm}, \mathrm{~W}=15 \mathrm{~mm}, \mathrm{t}=1 \mathrm{~mm})$....

Figure 3: Fatigue life variability of Ti-6Al-4V, showing samples with surface and internal initiation

Figure 4: SEM fractographs at 300x magnification of four samples, white circles indicate the initiation area; a $3.4 \times 10^{7}$ cycles to failure (sample $\mathrm{s}$ ); b $2.6 \times 10^{7}$ cycles to failure (sample A); c $9.6 \times 10^{7}$ cycles to failure (sample C); $d 5.7 \times 10^{7}$ cycles to failure (sample B)

Figure 5: SEM fractographs at 2000x and $20000 x$ magnification of two selected samples; a $2.6 \times 10^{7}$ cycles to failure (sample A, subsurface); b $5.7 \times 10^{7}$ cycles to failure (sample B, fish-eye)....

Figure 6: SEM fractographs of sample B $\left(5.7 \times 10^{7}\right.$ cycles to failure), taken at the same location on both opposite fracture surfaces (left and right)

Figure 7: Rounded fractographic features on the fracture surface of a subsurfaceinitiated Ti-6Al-4V sample ${ }^{36}$

Figure 8: 1010 pole figure of alpha phase, obtained from an EBSD measurement on sample cross-section, wire axis is perpendicular to the paper... 10

Figure 9: Distribution of spatial angle of facets (between facet plane and normal direction) for both sample A (subsurface, $2.6 \times 10^{7}$ cycles to failure) and sample B (fisheye, $5.7 \times 10^{7}$ cycles to failure)

Figure 10: Representation of crystal orientation present in the texture of the wire, and the six prismatic planes of the hexagonal lattice....

Table 1: Chemical composition of the wire, as determined by the manufacturer (wt-\%) . 4 